\title{
Occurrence and Three-Dimensional Structure of Multiple Synapses between Individual Radiatum Axons and Their Target Pyramidal Cells in Hippocampal Area CA1
}

\author{
Karin E. Sorra ${ }^{1}$ and Kristen M. Harris ${ }^{1,2}$ \\ 'The Program in Neuroscience, Harvard Medical School, and '2Department of Neurology, Children's Hospital, Boston, \\ Massachusetts 02115
}

Recent physiological work has used quantal analysis to investigate the properties of synaptic transmission and longterm potentiation in hippocampal area CA1. These analyses have revealed changes in the strength of excitatory postsynaptic responses following long-term potentiation that could be mediated by cellular mechanisms in the presynaptic element, in the postsynaptic element, or in both elements. In these studies, either minimal stimulation, presumably involving a single presynaptic axon, or recordings from pairs of CA3 and CA1 cells have been used. Interpretation of these quantal analyses requires knowledge about whether single or multiple synapses occur between the presynaptic axon and its target CA1 pyramidal cells. Here, light and serial electron microscopy was used to begin to examine this question and a related question concerning the ultrastructure of spines on multiple-synapse boutons.

Light microscopic analyses of Golgi preparations revealed that about $20 \%$ of the axons occurring in stratum radiatum come into close apposition with two to four different dendrites of a target CA1 cell. An "apposition" was defined as a point where the axons and dendrites crossed in the same focal plane and therefore were sufficiently close to allow a dendritic spine to reach the axon and possibly establish a synaptic contact. An additional $4 \%$ of the axons wound back and forth across individual dendrites, possibly forming multiple synapses closely spaced along the dendrites. Serial electron microscopy revealed that $24 \%$ of the individual axonal boutons in stratum radiatum make synapses with multiple dendritic spines arising from either the same or different dendritic segments. Two adjacent boutons of the same axon could also be found to synapse with different spines of the same dendrite. Together with the light microscopic analysis, these observations suggest that multiple synapses occur between single axons in stratum radiatum and their target

\footnotetext{
Received Nov. 12, 1992; revised Mar. 8, 1993; accepted Mar. 18, 1993.

We thank Dr. Stuart Tobet for his assistance and for the use of the IBAS reconstruction system in the Morphological Imaging Facility, E. K. Shriver Center, to display the Golgi images. We thank Dr. Jeffrey Macklis for assistance with the light microscopy and along with Dr. John Lisman for many helpful comments on an earlier version of the manuscript. We thank Dr. John Davis for improving the software utilized to make the three-dimensional reconstructions. This work is supported by NIH-NINCDS NS21 184, The Alfred P. Sloan Foundation and the MR Center Grant P30-HD18655 from NICHD (K.M.H.), and by the Division of Medical Sciences, Harvard Medical School (K.E.S.).

Correspondence should be addressed to Kristen M. Harris, Ph.D., Department of Neurology, Children's Hospital, Enders 208, 300 Longwood Avenue, Boston, MA 02115.
}

Copyright (C) 1993 Society for Neuroscience $0270-6474 / 93 / 133736-13 \$ 05.00 / 0$
CA1 cells, and that at least some of these synapses may occur at different electrotonic distances. If these multiple synapses have different physiological strengths, then they may obscure or smooth peaks in the frequency histograms that are used for quantal analyses.

A three-dimensional analysis was done to compare the dimensions of pairs of dendritic spines synapsing with individual axonal boutons. When the pairs of spines associated with a single bouton arose from different dendrites, at least some of which were likely to have come from different cells, the differences between their volumes and the areas of the postsynaptic densities were on average $100 \%$ and ranged up to $650 \%$. This finding suggests that the presynaptic axon alone does not determine the morphology of its postsynaptic partner. In contrast, when the pairs of spines could be traced to the same postsynaptic cell ( $n=6$ pairs) they had volumes and postsynaptic density areas that differed by only $35 \%$ on average and not more than $81 \%$. This intriguing observation suggests that coactivation of the preand postsynaptic cell may be an important factor in determining spine and synapse morphology in area CA1.

[Key words: dendritic spines, Golgi, serial electron microscopy, axonal boutons, postsynaptic density, reconstruction, quantal analysis, long-term potentiation]

Many studies of synaptic transmission in the hippocampus have focused on the phenomenon of long-term potentiation (LTP), a form of plasticity that results in enhanced synaptic transmission that can last for hours to days following repeated or appropriately patterned afferent stimulation. In hippocampal area $\mathrm{CA} 1$, the induction and early expression of the potentiation are known to involve several presynaptic and postsynaptic components, while the mechanism(s) of enduring LTP remains controversial. Recent physiological findings suggest that synaptic transmission at excitatory CA1 synapses is quantal in nature and that potentiation occurring at least during the first hour posttetanus may have a predominantly presynaptic component (Bekkers et al., 1990; Malinow and Tsien, 1990; Voronin et al., 1990; Malinow, 1991). In contrast, other experiments also using quantal analysis in area CAl suggest that the potentiation is due to an increase in quantal size that is generated postsynaptically (Foster and McNaughton, 1991; Manabe et al., 1992). Recent experiments have shown that both pre- and postsynaptic mechanisms may be involved depending on the state of the synapse prior to induction (Kullman and Nicoll, 1992; Larkman et al., 1992). 
In order to perform these physiological experiments, either minimal stimulation of axons in stratum radiatum (s. radiatum) or recording from pairs of synaptically connected CA3 and CA 1 cells is used. Minimal stimulation involves positioning an electrode in the middle of $s$. radiatum as far from the recording site as possible in an attcmpt to activate just one fiber (Larkman et al., 1991; Kullman and Nicoll, 1992). The stimulus strength is adjusted to give frequent apparent failures so that the assumption can be made that when an activation does occur it is of a single axon. Under these circumstances, LTP is assumed to result from enhancement of the efficacy at a single synapse. Interpretation of the amplitude histograms can then be used to determine whether the changes occur pre- or pustsynaptically. Intracellular or whole-cell patch recording from an individual CA 1 cell, followed by impalement of CA 3 cells until one is found to activate the CAl cell, is used to achieve recordings from pairs of synaptically connected cells (Sayer et al., 1990; Malinow, 1991). At issue is whether minimal stimulation or paired cell stimulation activates one or more than one synaptic connection between two cells (Redman, 1990; Bekkers and Stevens, 1991; Edwards, 1991; Korn and Faber, 1991). If more than one connection is activated, then LTP could involve the strengthening or recruitment of new synapses that were initially very weak or silent, instead of, or in addition to, strengthening the first synapse. To improve interpretation of these physiological findings, the uncertainty of whether the responses could involve one or more synapses needs to be resolved.

The neuronal circuitry of the hippocampus has been studied since the turn of the century (Ramon y Cajal, 1911; Lorente de No, 1934; Amaral and Whittier, 1989). It is known that the CA3 pyramidal cell axons have many varicosities along their length and that they form excitatory en passant synapses primarily onto dendritic spines of the CA1 pyramidal cells (Westrum and Blackstad, 1962; Andersen et al., 1966a,b). One set of CA3 axons, the Schaffer collaterals (Schaffer, 1892), traverses s. radiatum of the ipsilateral area $\mathrm{CAl}$, and a second population of $\mathrm{CA} 3$ axons, the commissurals, branch and project to $\mathrm{s}$. radiatum of the contralatcral hippocampus (Blackstad, 1956). Other inputs to CAl pyramidal cells in s. radiatum include associational fibers from CA3 cells in adjacent lamellae, and cholinergic fibers from the medial septum that terminate close to the pyramidal cell body layer (Andersen et al., 1961; Powell, 1963; Frotscher et al., 1986). Axons from interneurons are also present in s. radiatum; however, their frequency is relatively low and their synapses occur primarily onto dendritic shafts and cell somas of both the CAl pyramidal cells and other interneurons (Schlander and Frotscher, 1986). Depending on the specific trajectory of the radiatum axons in a particular hippocampus, minimal stimulation in s. radiatum could activate any of these axons.

No studies have yet been done to determine the number of synapses made between single radiatum axons and their target CAl pyramidal cells. An earlier estimate, based on the dendritic branching patterns, the approximate trajectories of the radiatum axons, and the interbouton distances, suggested that on average 1.3 contacts could be made for each axonal collateral (Andersen, 1990). Ideally, recordings from a single pair of pre- and postsynaptic cells followed by injections of an electron-dense dye and examination at the electron microscopic (EM) level would be used to determine directly the frequency of multiple synapses between these axons and their target CAl cells, and their relative efficacies. This approach has not yet been done and will be technically demanding, given the low frequency with which pairs of cells can be recorded from (Friedlander et al., 1990; Sayer et al., 1990; Foster and McNaughton, 1991; Malinow, 1991).

Since numerous physiological studies are presently utilizing quantal analyses that rely on minimal stimulation or pairedcell recordings, it is important to establish with greater certainty whether more than one synapse can occur between a radiatum axon and its target CAl cells. An approach was adopted here wherein populations of CA1 pyramidal cells and radiatum axons were evaluated in two sets of tissue that were available from other experiments. First, light microscopic (LM) analysis of Golgi-impregnated neurons from Harris et al. (1980) was used to evaluate the likelihood of multiple contacts between radiatum axons and different dendrites of single CA1 pyramidal cells. Next, serial electron micrographs from Harris et al. (1992) were used to determine the frequency with which individual axonal boutons synapse with more than one dendritic spine and whether these spines arose from the same or different dendrites and/ or cells. The boutons that make more than one synapse are called multiple-synapse boutons (MSBs).

The dimensions of pairs of spines synapsing with the MSBs were compared through three-dimensional reconstruction to determine the relative degree of similarity among the pairs arising from the same or different dendrites (Harris and Stevens, 1989; Harris et al., 1992). If activation or other chemical signaling by the presynaptic axon alone were sufficient to determine the morphology of the postsynaptic spine, then both spines in all pairs of spines that synapse with MSBs should have the same morphology whether they arose from dendrites on the same or different CA1 cells. If however, coactivation of the pre- and postsynaptic cells is required to mold spine and synapse morphology, then pairs of spines occurring on the same CA1 cell should be more similar to one another than pairs of spines occurring on different CA1 cells.

\section{Materials and Methods}

Light microscopy of Golgi-impregnated hippocampus. In earlier work (Harris et al., 1980), the rapid Golgi method was used on hippocampal slices from adult Long-Evans rats of both sexes (50-60 d old). In the present study, well-impregnated radiatum axons and CAl pyramidal cells from these slices were viewed using a $63 \times$ Neofluor oil immersion lens with a numerical aperture of 1.25. The final magnification of $1260 \times$ was achieved through a $2 \times$ optivar and $10 \times$ eyepieces on a Zeiss light microscope. The depth of field was calculated to be $0.27 \mu \mathrm{m}$ using the formula supplied by Zeiss: $D=(1000 /(7 \times$ N.A. $\times \mathrm{TM}))+(\lambda /(2$. N.A. $\left.{ }^{2}\right)$ ), where $D$ is depth of field, N.A. is numerical aperture, TM is total magnification, and $\lambda$ is wavelength of light $(550 \mathrm{~nm}$ was used as the middle of the range of visible light). The IBAS image analysis system (Zeiss/Kontron) was used to photomontage axons and their point(s) of close apposition with dendrites of a single CA1 pyramidal cell as a uniformly focused image. A Neofluor $100 \times$ oil immersion lens was used for the illustrations in the Figures 1-3. This lens has an N.A. of 1.3 , and at the final magnification of $1000 \times$ also has a $0.27 \mu \mathrm{m}$ depth of field. By way of caution, the depth of field calculated here is the theoretical depth of field for these objective lenses; the perceived depth of field may be greater (see Results).

Serial electron micrographs. Serial electron micrographs from Harris et al. (1992) were used to evaluate the relative frequencies of multiplesynapse boutons (MSBs) and single-synapse boutons (SSBs) in s. radiatum. Details of their preparation are available in Harris et al. (1992). Briefly, the animals were perfused under deep pentobarbital anesthesia with fixative containing mixed aldehydes and processed for electron microscopy. Thin sections were obtained utilizing a diamond knife, at a Reichert Ultracut III ultramicrotome, and section thickness was determined as described in Harris et al. (1992) to range from 0.055 to $0.11 \mu \mathrm{m}$ depending on the series utilized. The electron micrographs were located $200-250 \mu \mathrm{m}$ from the CA1 pyramidal cell body layer in a 70-d-old male rat of the Long-Evans strain. Three series were assessed, consisting of 68,53 , and 27 sections, respectively. In addition, MSBs 
from Harris and Stevens (1989), also located 200-250 $\mu \mathrm{m}$ from the CAl cell layer, were used to compare similarities and differences among pairs of spines synapsing with the MSBs.

Three-dimensional reconstructions, editing, measurement, and display of MSBs, dendritic spines, and PSD surface areas. Reconstructions were obtained by positioning the electron micrographs under a video camera, capturing the image in a Gould frame grabber that was interfaced to a VAX $11 / 780$, and using AUTOTRACE software, developed at Children's Hospital Image Graphic Laboratory (IGL) to trace the neuronal membrane and the postsynaptic densities (PSDs). The images of adjacent sections were microaligned by switching between the stored image and the live image and moving the live image to minimize motion of all the structures in the field (Harris and Stevens, 1988, 1989; Harris et al., 1992). The program PANDORA, also developed in the IGL (Pearlstein et al., 1986), was used to edit and analyze the reconstructions quantitatively. An Interactive Computerized Analysis Reconstruction System (ICAR, ISG Technologies, Mississauga, Ontario, Canada) was used to display, rotate, and photograph the reconstructed images.

The total area of each PSD was measured through serial sections. For cross-sectioned synapses, the PSD area equaled its length on adjacent sections multiplied by section thickness and added across sections. For obliquely sectioned PSDs, the enclosed areas were measured and if more than one adjacent section contained portions of the PSD, a connector was drawn where the area overlapped and the total area equaled the enclosed areas plus the length of each connector multiplied by the section thickness. The volumes of dendritic spines were computed by multiplying the area of each contour that contained cytoplasm, by the section thickness and adding half the computed volume for any edge sections containing the gray wall of the plasmalemma, as described in previous publications (Harris and Stevens, 1988, 1989; Harris et al., 1992). The RSI statistical package (Bolt, Beranek and Newman, Cambridge, MA) was used for all statistical analyses.

\section{Results}

Light microscopy. In the Golgi preparations, CAl pyramidal cells and axons coursing through their dendritic arbors were well impregnated, affording the opportunity to evaluate whether individual axons came into close apposition with one or more dendrites of a single CAl cell. When the axons and the dendrites intersected in the same focal plane, the crossing was defined as an "apposition." We estimated that the perceived depth of field is unlikely to be greater than $0.5-0.7 \mu \mathrm{m}$ because we could perceive different parts of individual dendritic spines and axonal boutons as in or out of focus. Since our earlier studies (Harris and Stevens, 1989) established CAl spines to be on average $0.95 \mu \mathrm{m}$ long, this seemed an appropriate estimate for the perceived depth of field. In any case, dendrites and axons observed crossing within this focal plane will be sufficiently close to one another such that a synapse could form, though serial EM examination is required to show that a synapse indeed occurs (see below).

The CA 1 pyramidal cells were identified by their location and their spiny apical and basilar dendrites. This region of the CAl apical dendritic field is illustrated in Figure $1 a$. Axons in s. radiatum were thinner than dendrites, were spine-free, had varicosities along their lengths, and coursed through s. radiatum perpendicularly to the apical dendrites of the CA1 pyramidal cells. Since the Schaffer collateral, commissural, and associational fibers are intermingled in s. radiatum and cannot be distinguished in the Golgi preparations, they were considered as a single population of radiatum axons. Similarly, physiological studies in hippocampal slices that use stimulating electrodes positioned in this part of the field can also activate any of these axons.

Eighty-five well-impregnated axons were located in s. radiatum between 19 and $370 \mu \mathrm{m}$ from the apical edge of the CAl pyramidal cell body layer. The total height of the apical dendritic fields ranged from about 370 to $600 \mu \mathrm{m}$ from the cell bodies to the hippocampal fissure; none of the 85 axons occurred among the outer third of a particular dendritic arbor where the perforant path input predominates. The most proximal axons may have included among them some cholinergic inputs. Individual axons were followed in the LM as they traversed the entire breadth of an apical dendritic arbor of a single CA1 pyramidal cell (Fig. 1a). All of the dendritic branches coming into apposition with a single axon were followed, through focus, to confirm their origin at a single CAl pyramidal cell.

These axons were observed to make a single apposition on one dendrite $(76 \%)$ or multiple appositions $(24 \%)$ on up to four dendrites of a CAl cell (Table 1). An apposition was classified as "single" when only one crossing of the dendrite was observed (Fig. $1 b, c$ ). However, at this resolution it was impossible to determine whether synapses were formed on adjacent spines just beneath the axonal bouton (see the EM analysis below). Similarly for cases of axons in apposition with two dendrites (Fig. 2a,b), three dendrites (Fig. 2c,d), and four dendrites (Fig. $2 e$ ), it could not be determined whether each apposition might involve single or multiple synapses. Three axons wound back and forth across a single dendrite and apposed multiple dendritic spines, thus suggesting that an individual axon can form multiple synapses on a single dendrite (Fig. 3). With LM, it could not be determined whether any of the appositions defined here actually made synapses with the postsynaptic dendrites. However, these LM observations support the hypothesis that individual radiatum axons may form multiple synapses onto the same and different dendrites of a single CAl pyramidal cell, an observation that is confirmed as part of the EM analysis presented next.

Serial electron microscopy. Serial electron micrographs (from Harris and Stevens, 1989; Harris et al., 1992) were used to determine whether individual axonal boutons in $s$. radiatum actually form synapses with more than one postsynaptic dendritic spine. Several examples of two spines from the same dendrite were found to receive synaptic input from a single axonal bouton. The synapses had thickened PSDs and the presynaptic axon contained clear round vesicles, a typical appearance for excitatory asymmetric synapses in this region (Westrum and Blackstad, 1962). In Figure 4, the dendritic spine profiles can be traced through serial sections to their origins at a single dendrite. These synapses would have been classified as "single appositions" in the LM analysis above. A second example illustrates that adjacent boutons of a single axon can also form synapses onto spines from the same parent dendrite (Fig. 5; see also Fig. 7). These synapses may have been recognized as "multiple appositions onto the same dendrite" in the LM analysis. Together, these observations suggest that the LM analysis may have underestimated the frequency of multiple synapses between individual radiatum axons and their target CAl pyramidal cells.

Quantitative analysis of the frequency of $M S B$ s. A quantitative analysis was completed to ascertain the relative frequencies of single- and multiple-synapse boutons in s. radiatum. Each axonal bouton that had a synapse on the central reference section was viewed through serial sections to determine whether it made just this single synapse (SSB) or if multiple synapses were formed by the bouton (MSB). As illustrated in Figure 6, only two MSBs had both of their synapses transected by this part of the reference section. Ten of the other boutons on this part of the reference section were found to be MSBs, through serial section viewing, though they appear as SSBs on the reference section. The fre- 

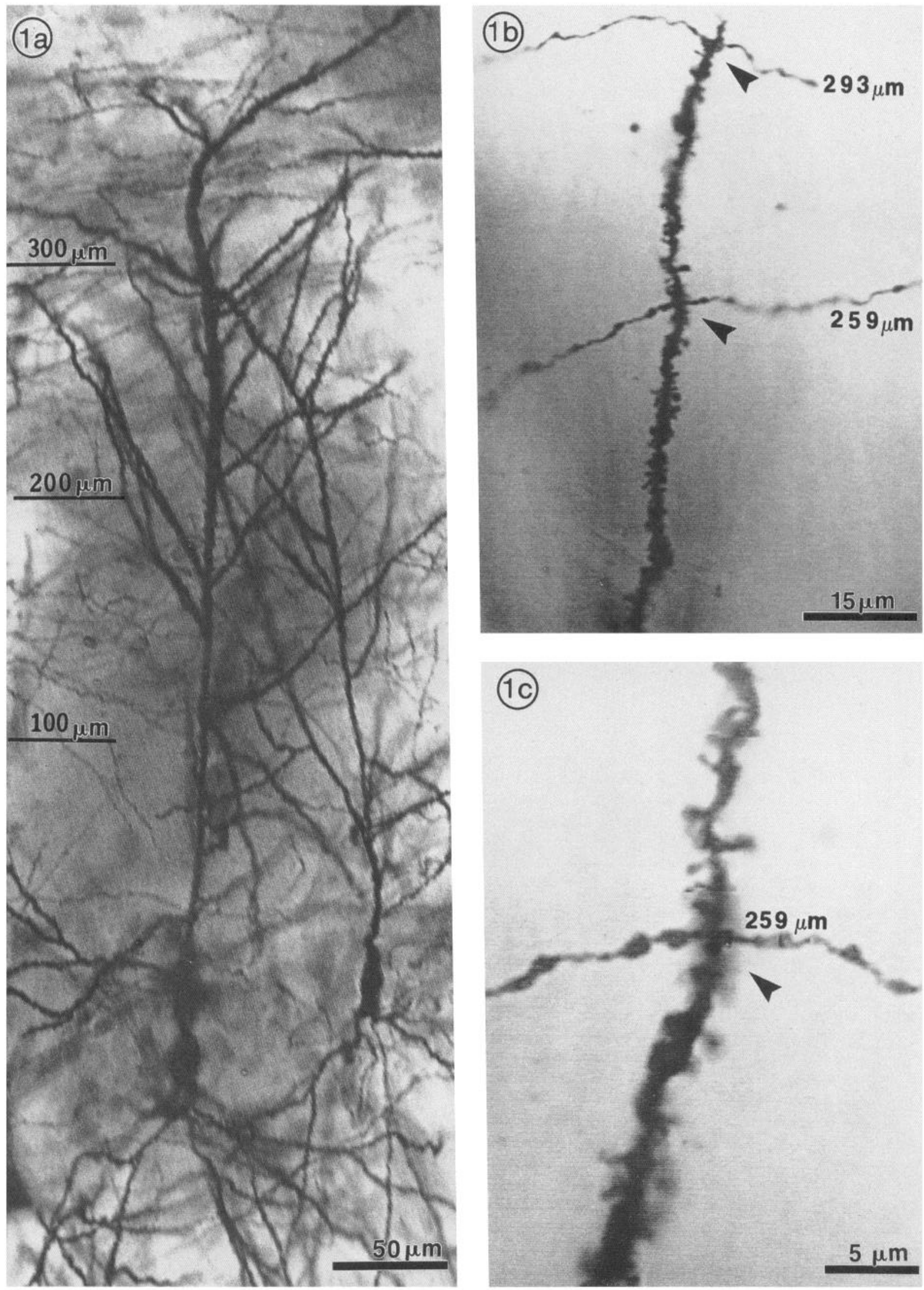

Figure 1. Golgi-impregnated CA1 pyramidal cells and axons in s. radiatum. $a$, Two CA1 pyramidal cells and the radiatum axons that traverse their apical dendritic arbors. Distance from the cell body layer is indicated on the left. $b$, Radiatum axons making single appositions. The arrowheads identify single appositions at $259 \mu \mathrm{m}$ and $293 \mu \mathrm{m}$ from the cell body layer. $c$, Higher magnification of the apposition at $259 \mu \mathrm{m}$. 

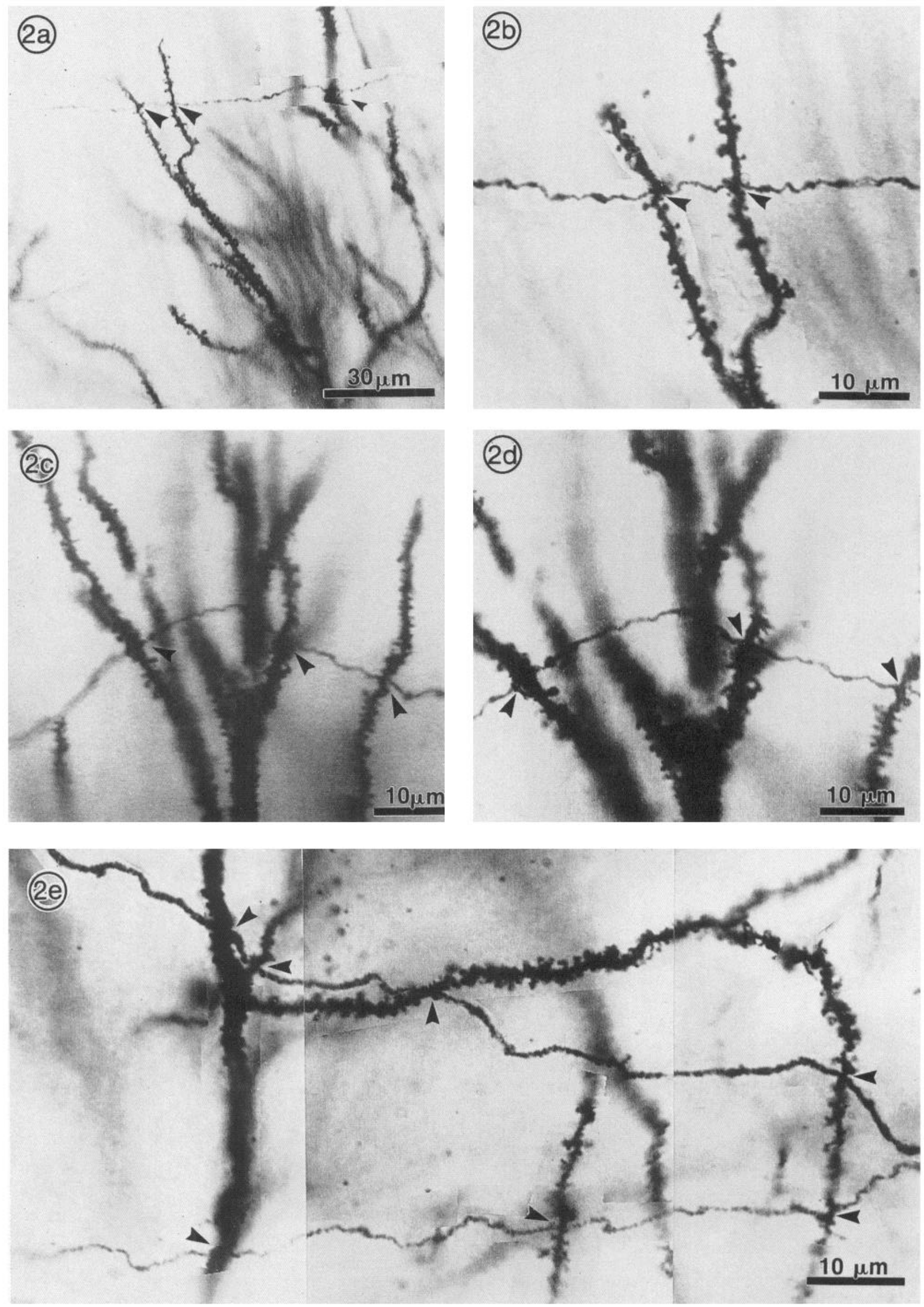

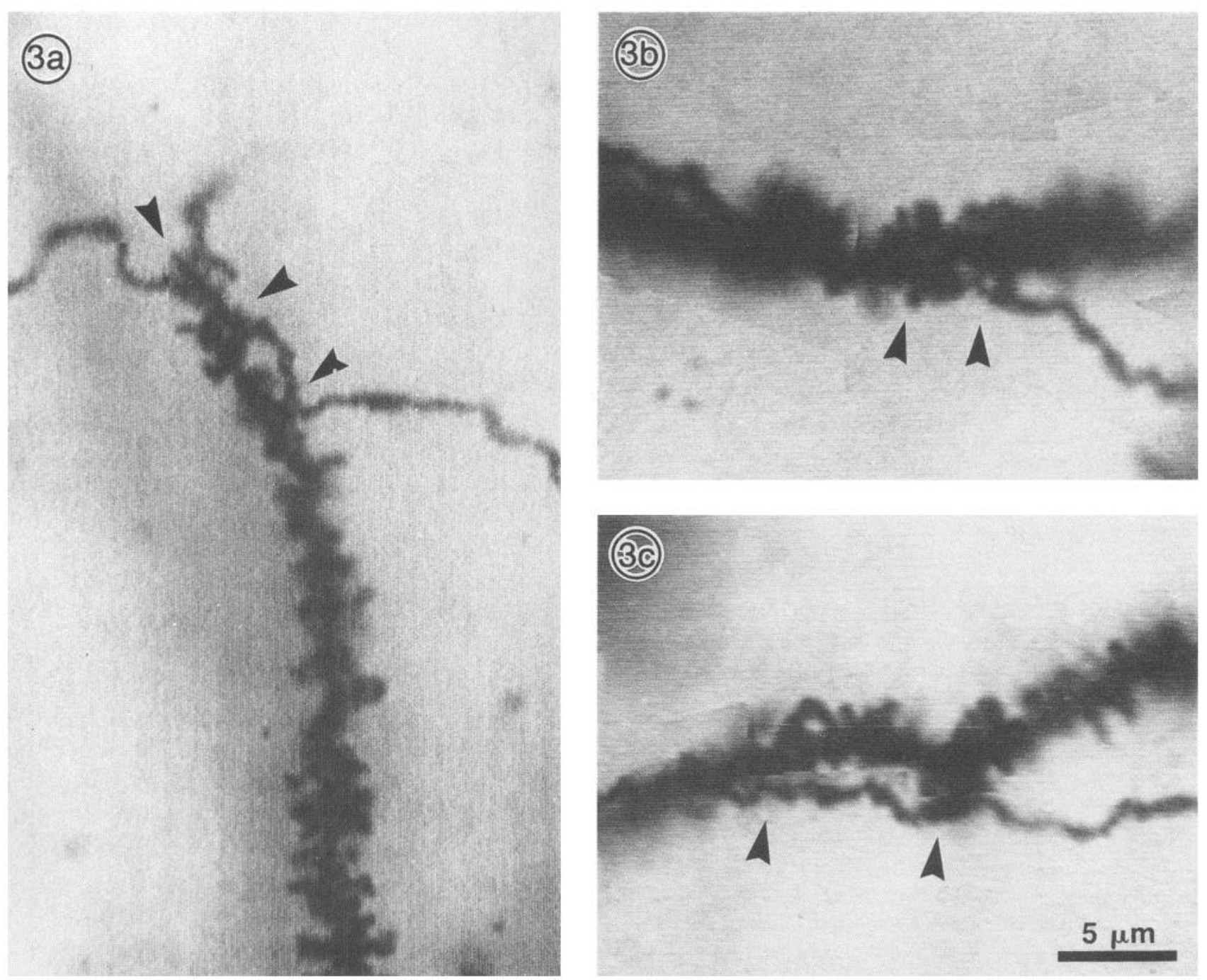

Figure 3. Photomontages of multiple appositions (arrowheads) between single radiatum axons and individual CAl pyramidal cell dendrites. These radiatum axons were located as follows: $a, 248 \mu \mathrm{m} ; b, 207 \mu \mathrm{m}$; and $c 43 \mu \mathrm{m}$ from the pyramidal cell body layer. Scale bar in $c$ is for $a-c$.

quency of MSBs was determined in relation to the total number of boutons in order to establish an upper limit for multiple synapses that would have appeared as "single appositions" in the LM.

A total of 202 axonal boutons were analyzed on the three EM series. Of these, 49 (i.e., 24\%) were MSBs (Table 2). All but two of these MSBs formed synapses onto two dendritic spines; the other two made synapses onto three dendritic spines. The frequency of MSBs identified on the single reference sections averaged only $4 \%$, in contrast with the $24 \%$ of the same boutons that actually formed multiple synapses when viewed through serial sections (Table 2). This discrepancy emphasizes the importance of examining serial electron micrographs to determine accurately the features of synaptic connectivity in the neuropil.
Three-dimensional viewing to ascertain dendritic origins. All of the 100 dendritic spines that synapsed with the 49 MSBs were traced through serial sections, where possible, to their origins with CA1 pyramidal cell dendrites. The pairs of spines synapsing with 21 MSBs could be traced to different dendritic segments; with 4 MSBs, to the same dendrite; and with 2 MSBs, to different dendrites on the same cell. The origins of spines synapsing with the remaining 22 of the MSBs were not complete within the series. Since the width of the photographic fields was about $25 \mu \mathrm{m}$ and the length of continuous serial sections was less than $5 \mu \mathrm{m}$, it was impossible to ascertain whether the other "different" dendritic segments arose from the same or from different cells, except for the two spine pairs mentioned above. These two pairs confirm that spines on different dendrites of

Figure 2. Multiple appositions by single radiatum axons onto different dendrites of their target CA1 pyramidal cells. $a$, Two appositions (large arrowheads) onto two different dendrites of the same CA1 pyramidal cell revealed through photomontage in the same focal plane at low magnification. The dendrites were followed through focus to confirm their origin at the same pyramidal cell. The apposition indicated by a small arrowhead at the right of the figure is on a dendrite of a different pyramidal cell. $b$, The two appositions in $a$ at higher magnification; the axon was located 263 $\mu \mathrm{m}$ from the pyramidal cell body layer. $c$ and $d$, Low and high magnification of three appositions onto three different dendrites of the same CAl pyramidal cell. This axon was located $259 \mu \mathrm{m}$ from the pyramidal cell body layer. $e$, Photomontage of radiatum axons located $19 \mu \mathrm{m}$ and $43 \mu \mathrm{m}$ from the pyramidal cell body layer making three and four appositions, respectively (arrowheads), onto dendrites of the same CA1 pyramidal cell. 

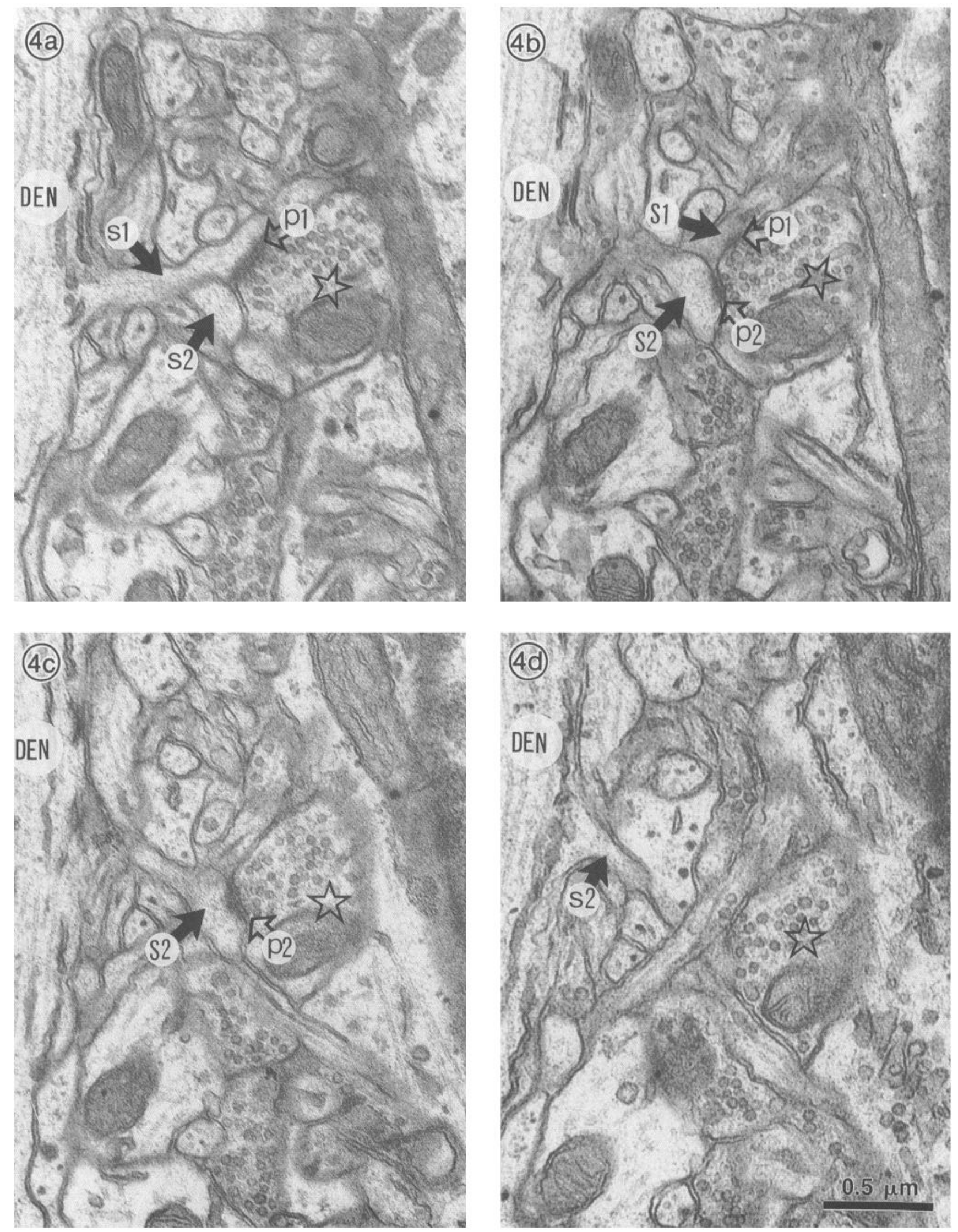

Figure 4. An MSB (star) in area CAl synapsing with two neighboring dendritic spines of the same dendrite $(D E N)$. Serial sections $37-40$ of series k36 are illustrated in $a-d$, respectively. The MSB (star), two dendritic spines $(s 1, s 2)$, and their corresponding PSDs ( $p 1, p 2)$ are labeled where they are found in each section. The origin of spine $1(s 1)$ occurs in section $37(a)$ and the origin of spine $2(s 2)$ occurs on the same dendrite in section $40(d)$. These prints were enlarged 12-fold from the original negatives to illustrate the MSB (and hence have a somewhat "grainy" appearance); the scale bar in $d$ is for $a-d$. 

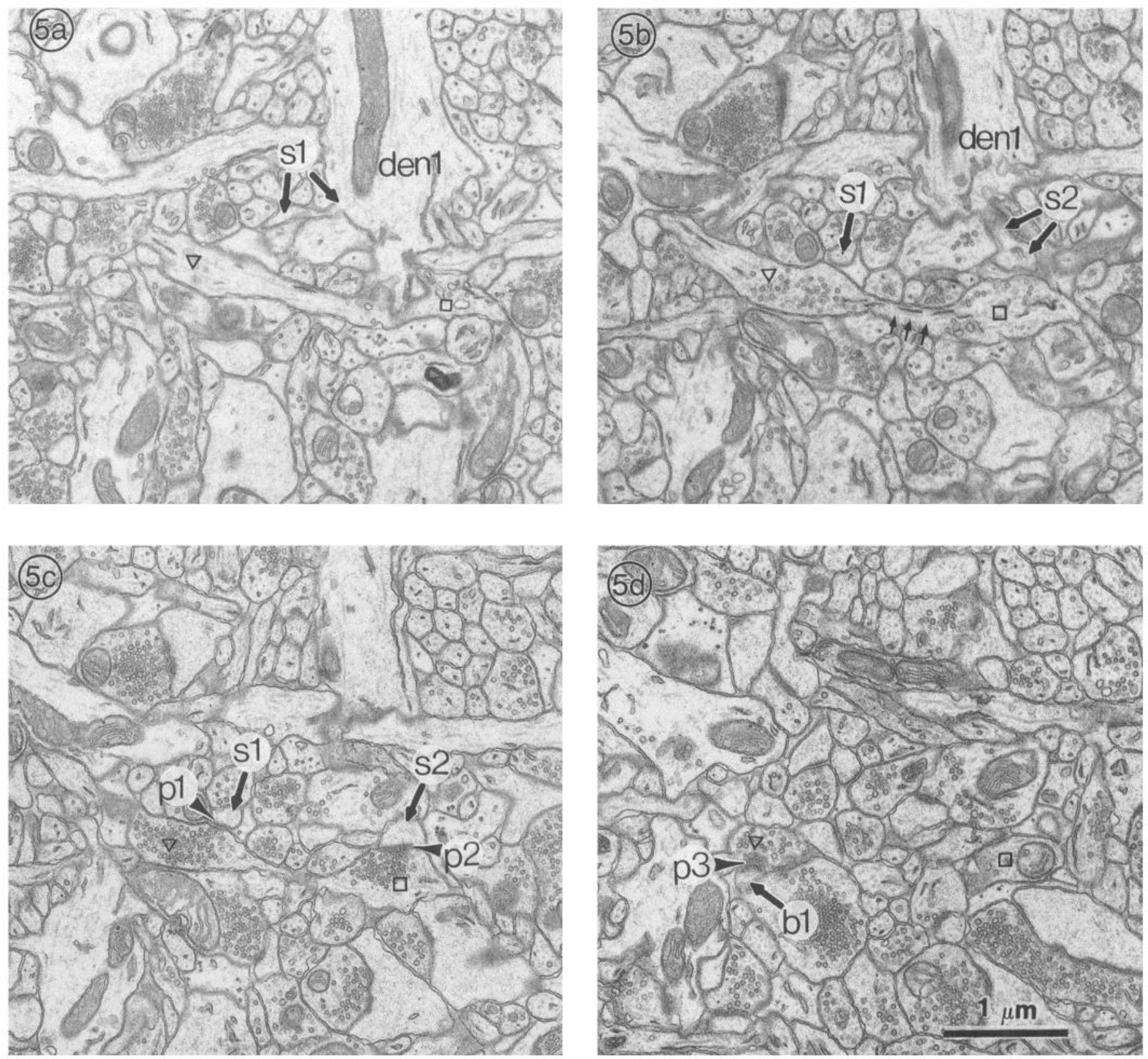

Figure 5. Adjacent axonal boutons synapsing with two dendritic spines from the same parent dendrite and with one dendritic spine from a different dendrite (see also reconstruction in Fig. 7). Sections 27, 30, 32, and 36 of series k34 are illustrated, respectively, in $a-d$. The axon is longitudinally sectioned, and two adjacent axonal boutons are identified by triangles and squares. $a$, In this section the origin of spine 1 ( $s 1)$ on dendrite 1 (den 1 ) can be seen. $b$, Here the axonal boutons contain synaptic vesicles and are connected by a constricted interbouton region of the axon (three small arrows). The head of spine $1(s 1)$ and the origin of spine $2(s 2)$ with dendrite $1($ den 1$)$ are present. $c$, The axonal boutons are filled with vesicles in this section and appear as two separate profiles that synapse with the dendritic spine heads ( $s 1$ and $s 2)$. Synapses and PSDs ( $p 1, p 2)$ are also indicated. $d$, This section is the reference section of the series where one of the axonal boutons makes another synapse onto the head of branch 1 (bl) of a different dendritic spine (s3 in Fig. 7). The scale bar in $d$ is for $a-d$ and matches that of Figure 7.

the same CA1 cell can form synapses with the same radiatum axon. It is presumed that some of the other parent dendrites arose from different cells based on the apparently divergent trajectory of the dendrites and, conversely, that some dendrites arose from the same cells.

Comparison of the dimensions of pairs of spines on MSBs. Three-dimensional reconstructions have been obtained for 27 MSBs and their corresponding dendritic spines and PSDs (10 MSBs were randomly selected from the 49 observed here; 8 MSBs were from Harris and Stevens, 1989; 9 were from Harris
Table 1. Frequency of radiatum axons observed by LM to make single or multiple appositions with individual CA1 pyramidal cells

\begin{tabular}{llllll} 
& \multicolumn{6}{c}{ Multiple appositions on } \\
\cline { 3 - 6 } & $\begin{array}{l}\text { Single } \\
\text { appositions }\end{array}$ & 1 & 2 & 3 & 4 \\
Dendrite & Dendrites & Dendrites & Dendrites \\
\hline Number & 65 & 3 & 14 & 2 & 1 \\
$\%$ total & $76 \%$ & $4 \%$ & $17 \%$ & $2 \%$ & $1 \%$ \\
\hline
\end{tabular}




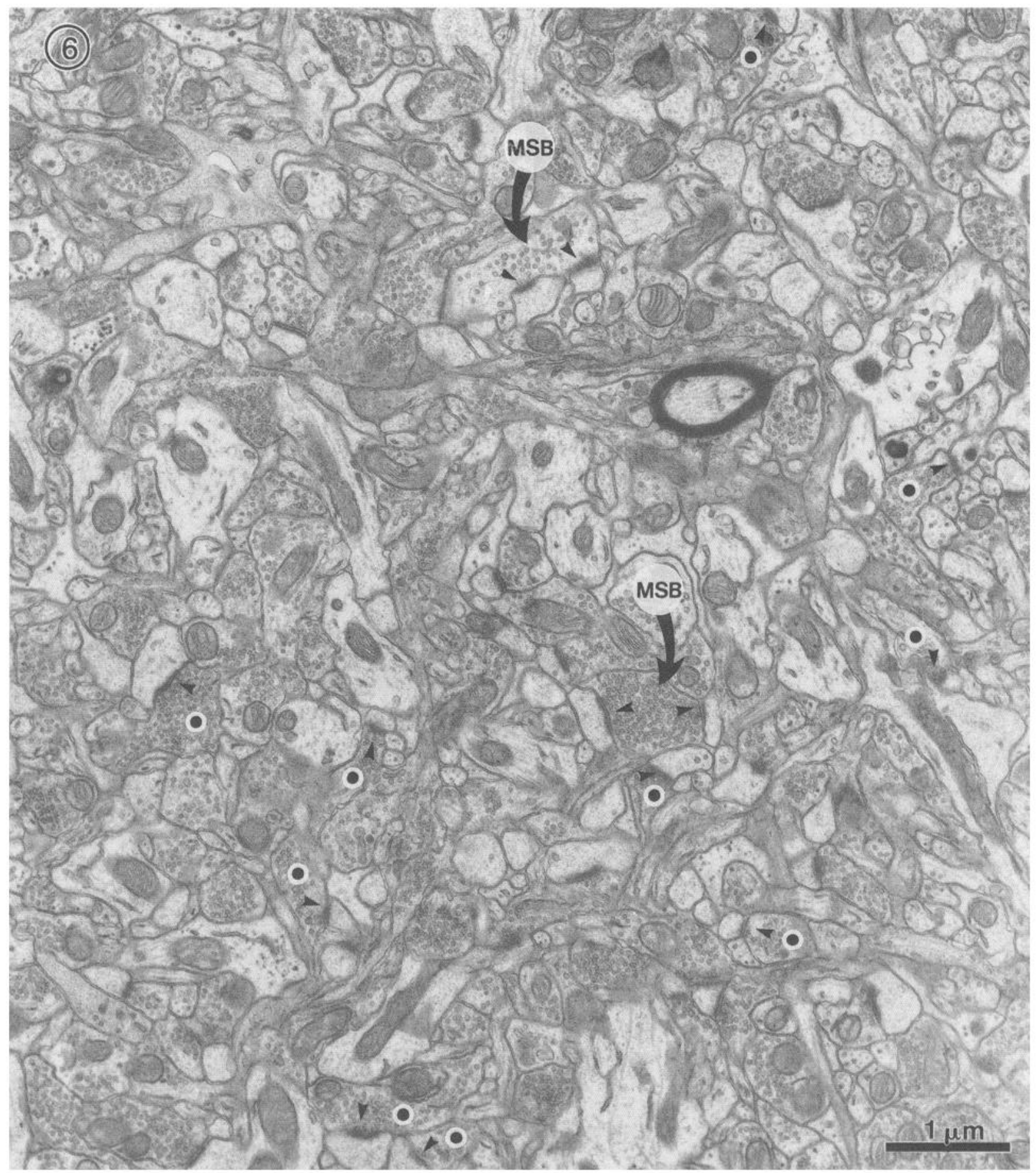

Figure 6. Part (approximately one-third) of the reference section for series k36. Two MSBs (curved arrows) have their PSDs transected by this reference section. Ten other axonal boutons (marked by solid circles) have only one synapse on this section, but when viewed through serial sections are correctly identified as forming multiple synapses (MSBS). For all of the MSBs, arrowheads point to the synapses from the presynaptic side. All of the other boutons with PSDs on this reference section were indeed SSBs when viewed through serial sections.

et al., 1992). Spines sharing the same bouton were observed to have both similar and different shapes. All shape classes, including thin, stubby, mushroom, and branched, could be observed, in pairs of all combinations, on single MSBs as illustrated in Figure 8. The pairs of spines in Figure 8, $a$ and $b$, arose from different dendritic segments and illustrate that spines with grossly different morphologies can synapse with a single bouton. The two thin spines in Figure $8 c$ arose from the same dendritic segment, while the large mushroom spine came from a different dendritic segment. The two spines in Figure $8 d$ arose from two different dendrites of the same CAl cell. One head on each of four branched spines synapsed with the reconstructed MSBs, and three are illustrated in Figures 7 and $8 c, d$.

The dimensions of the spines and PSDs were measured and compared pairwise for each MSB. Pairs of spines synapsed with 25 of the MSBs and triplets of spines synapsed with two of the 


\begin{tabular}{lllll}
\hline Table 2. Frequency of MSBs as revealed by serial section versus single section analyses \\
& Series k33 & Series k34 & Series k36 & Total \\
\hline $\begin{array}{l}\text { Total number of axonal boutons } \\
\begin{array}{l}\text { Serial section identification } \\
\quad \text { Number of MSBs }\end{array}\end{array}$ & 42 & 87 & 73 & 202 \\
$\quad \begin{array}{l}\text { Percentage of total that were indeed MSBs } \\
\text { Single section identification }\end{array}$ & $21 \%$ & 15 & 25 & 49 \\
$\quad$ Number of MSBs & & & $34 \%$ & $25 \%$ \\
$\quad$ Percentage of total identified as MSBs & 1 & $2 \%$ & 5 & 8 \\
\end{tabular}

Series numbers match those assigned for Harris et al. (1992).

MSBs for a total of 56 spines. For the branched spines, the PSD areas and volumes of just the branch that synapsed with the MSB were measured, because in no case did the second branch of the spine share the same MSB as the first branch. Fifty-six of the PSDs and 43 of the spines were complete in these series. The range in area for the $56 \mathrm{PSDs}$ was from 0.02 to $0.26 \mu \mathrm{m}^{2}$. The greatest difference $(650 \%)$ occurred between two spines with PSD areas of $0.02 \mu \mathrm{m}^{2}$ and $0.17 \mu \mathrm{m}^{2}$, respectively. These two spines were not complete in the series and hence the difference in their volumes could not be computed. The range in the total volumes of the 43 complete spines was from 0.015 to $0.27 \mu \mathrm{m}^{3}$. The greatest difference (330\%) occurred between a pair of spines with volumes of 0.04 and $0.16 \mu \mathrm{m}^{3}$. In sum, spines of all sizes and shapes with the full range in PSD areas could occur in pairs on individual MSBs.

Twenty-three pairs of spines synapsing with MSBs could not be traced to the same CA 1 cell (though as discussed above, some of these may indeed have come from the same cell), and six pairs of spines could be traced to the same CA1 cell (Table 3). A pairwise comparison of the 23 pairs of spines of unknown origin revealed an average difference of about $100 \%$. This is in marked contrast with the less than $40 \%$ average difference in the dimensions of spine pairs known to originate from the same cell (Table 3). Since this number is small, no statistical evaluation of the contrast is made. However, 8 of the $23(35 \%)$ pairs of spines from unknown origin showed greater than $100 \%$ difference in their dimensions; therefore, two of six pairs would be predicted to have greater than $100 \%$ differences. None of the six pairs of spines arising from the same CAl cells had greater than $81 \%$ difference in their dimensions. These observations suggest that both sharing of a presynaptic axon and arising from the same postsynaptic cell may lead to spines of more similar morphologies than sharing only a presynaptic bouton or arising only from the same postsynaptic dendrite.

\section{Discussion}

These results extend our understanding of the connectivity between axons in s. radiatum and their target CAl pyramidal cells. LM examination of Golgi impregnated neurons revealed that $20 \%$ of the radiatum axons come into close apposition with more than one dendrite of individual CAl pyramidal cells. While this LM analysis cannot unequivocally establish the existence of synapses, the results certainly suggest that multiple synapses may be made by a single radiatum axon onto different CA1 dendrites. Analysis of serial electron micrographs revealed that $24 \%$ of the axonal boutons in s. radiatum form synapses with two or three dendritic spines. These MSBs would have been counted as single appositions in the LM and further suggest that up to $44 \%$ of the radiatum axons may be making multiple synapses on a single CAl pyramidal cell. This estimate includes only a single branch of each of the radiatum axons, though several collateral branches have been reported to emerge from axons in s. radiatum (Andersen, 1975, 1990; Tamamaki and Nojyo, 1991). The degree of collateral branching also depends on the age of the animal with younger animals having more collaterals (Swann et al., 1991). Since each of the axonal collaterals could make multiple synapses onto individual CAl pyramidal cells, the total frequency of multiple synapses between pairs of CA 3 and CA 1 cells could be higher than those estimated here, and could depend on the age of the animal. Together, these observations demonstrate that stimulation, which is restricted to even a single pair of synaptically coupled CA 3 and CA 1 cells, could activate multiple synapses on the target CAl cell.

If the pairs or triplets of spines synapsing with individual MSBs arose from different cells and had the same morphologies, then one might conclude that signals from the presynaptic axon alone are sufficient to produce the uniform postsynaptic structure. To evaluate this question, the area of the PSDs and the volumes of spines synapsing with individual MSBs were measured and compared pairwise. The PSD area provides an anatomical marker of synaptic strength because PSDs have been reported to contain neurotransmitter receptors, ion channels, and proteins that are fundamental for synaptic function (Kelly et al., 1984; Siekevitz, 1985; Kennedy et al., 1990). In addition, both the PSD area and the spine volume are highly correlated with the size of the axonal bouton and the total number of vesicles it contains (Harris and Stevens, 1989). Here we have shown that the difference in area between pairs of PSDs synapsing with MSBs ranges from $0 \%$ to $650 \%$, and from $6 \%$ to at least $330 \%$ for spine volume. These differences suggest that the

Table 3. Percentage differences in the dimensions of pairs of spines synapsing with the same MSB

\begin{tabular}{lll}
$\begin{array}{l}\text { Spine pair } \\
\text { location }\end{array}$ & PSD area & Spine volume \\
\hline Not traced to the & $98 \pm 140 \%$ & $96 \pm 87 \%$ \\
same CAl cell & $(0-650 \%)$ & $(6-330 \%)$ \\
& $(n=23)$ & $(n=15)$ \\
Traced to the & $37 \pm 31 \%$ & $35 \pm 25 \%$ \\
same CAl cell & $(0-81 \%)$ & $(8-77 \%)$ \\
& $(n=6)$ & $(n=6)$
\end{tabular}

Percentage differences in the dimensions were calculated as ( $\mid$ spine $1-$ spine $2 \mid$ smallest spine in the pair) $\left.{ }^{*} 100\right)$ and presented as the mean \pm SD with the full range in parentheses; $n=$ number of pairs evaluated. 


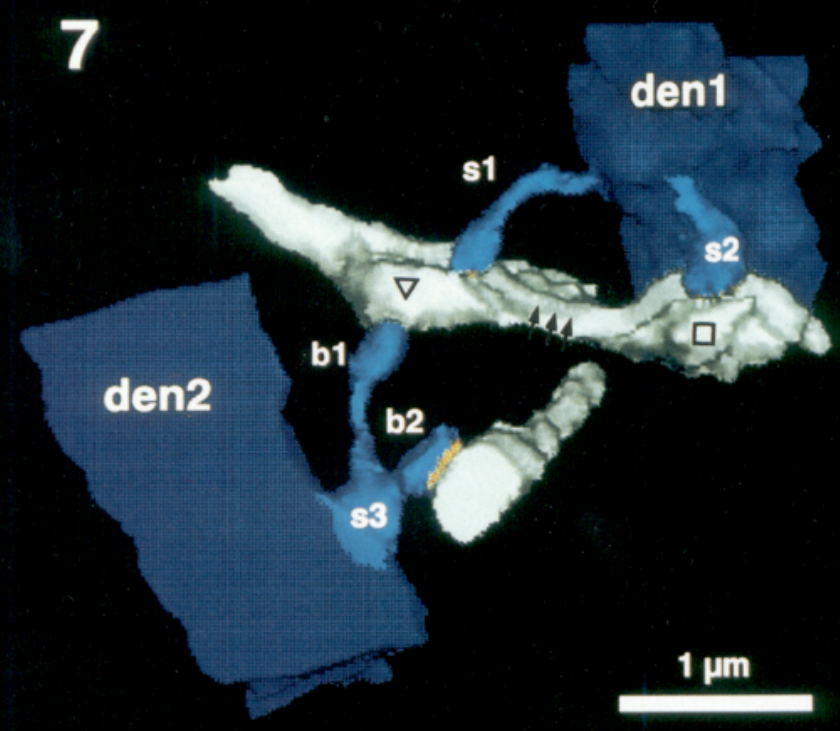

$8 a$

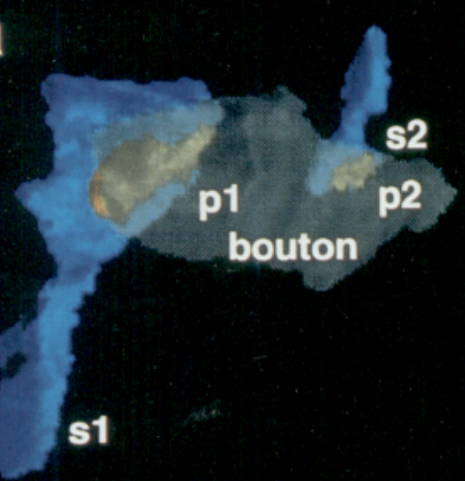

$8 b$

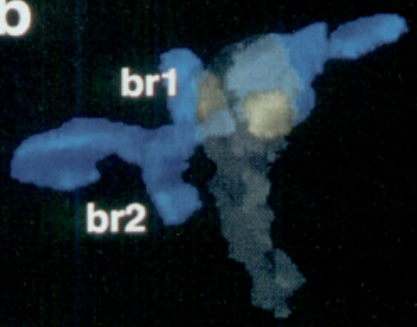

$8 c$

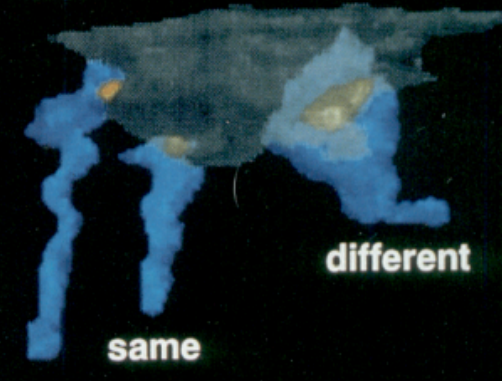

$8 d$

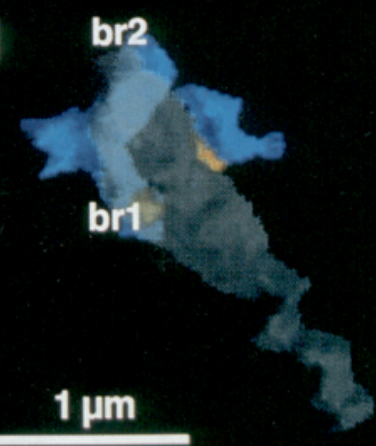


presynaptic axon alone is unlikely to determine the morphology of the postsynaptic partners, unless local signals exist within a single bouton. MSBs have a greater volume and contain more vesicles than nonsharing boutons, suggesting a greater synaptic demand on boutons with more than one postsynaptic element (Harris and Stevens, 1989). The question is whether this synaptic demand is shared equally among pairs of spines on an MSB. Perhaps a local presynaptic signal could arise from a nonuniform distribution of these vesicles or a nonuniform distribution in the number/size of release sites in the bouton, thereby creating an environment in which one spine on the MSB could be very large and the other very small.

When two spines from the same CA1 pyramidal cell synapsed with a single presynaptic axon, their morphologies were very similar. These results must be considered preliminary because many dendritic origins could not be determined. The observation is intriguing, however, in that it suggests that simultaneous pre- and postsynaptic coactivation of these pairs of synapses may result in their similar spine and PSD morphologies. Such a hypothesis is in accordance with Hebb's postulate (1949) that coactivation is required for the strengthening of synapses between cells, an event that is also necessary for the induction of LTP in hippocampal area CA1.

Considerable evidence has accumulated to suggest that the morphology of both the pre- and the postsynaptic components changes in response to LTP (for review, see Wallace et al., 1991). Controversy remains, however, as to whether the change reflects alterations in existing synapses and boutons or if new ones with different morphologies are formed (Harris et al., 1992). It has been reported from a single section analysis that the incidence of MSBs might decrease with LTP in the dentate gyrus (Desmond and Levy, 1990). Since a large difference occurs between counting MSBs on single versus serial EM sections, a different result could be obtained if their frequency following LTP were quantified by viewing them through serial sections. In addition, the frequency of branched spines has been reported to increase following LTP in area dentata (Trommald et al., 1990). Several of the MSBs evaluated in our study had the head of one branched spine as a postsynaptic partner. In all cases the second head of the branched spine synapsed with a different axonal bouton; therefore, it seems unlikely that branched spines in area CAl result from the splitting of a formerly single synapse into two spines.

All of the synapses occurring at either MSBs or SSBs may have quantal properties. However, if the multiple synapses occurring between two cells are not fired at the same time and strength, the resulting frequency histograms could be smoothed by the intermittent coincidence or asynchrony of activation. Thus, the occurrence of multiple synapses may explain why less than $30 \%$ of experiments, in which the EPSCs are recorded from
CAl cells, produce response histograms with clearly defined peaks (Kullmann and Nicoll, 1992). The observations presented here demonstrate that multiple synaptic connections occur between individual radiatum axons and their target CA1 cells. Evidence is also presented for both similar and dissimilar synaptic strengths among the multiple synapses. The results support the need to determine whether variable synaptic strengths occur among the multiple synapses of a particular pair of recordings in order to interpret subsequent quantal analyses.

\section{References}

Amaral DG, Witter MD (1989) The three dimensional organization of the hippocampal formation: a review of anatomical data. Neuroscience 31:571-591.

Andersen P (1975) Organization of hippocampal neurons and their interconnections. In: The hippocampus (Isaacson RL, Pribham $\mathrm{KH}$, eds), pp 155-175. New York: Plenum.

Andersen P (1990) Synaptic integration in hippocampal CA1 pyramidal cells. Prog Brain Res 83:215-222.

Andersen P, Bruland H, Kada BR (1961) Activation of the field CAl of the hippocampus by septal stimulation. Acta Physiol Scand 51: $29-40$.

Andersen P, Blackstad TW, Lomo T (1966a) Location and identification of excitatory synapses on hippocampal pyramidal cells. Exp Brain Res 1:236-248.

Andersen P, Holmqvist B, Voorhoeve PE (1966b) Excitatory synapses on hippocampal apical dendrites activated by entorhinal stimulation. Acta Physiol Scand 66:461-472.

Rekkers JM, Stevens CF (1991) Applications of quantal analysis to the study of long-term potentiation: errors, assumptions and precautions. In: Long-term potentiation: a debate of current issues (Baudry M, Davis JL, eds), pp 63-76. Cambridge, MA: MIT Press.

Bekkers JM, Richerson GB, Stevens CF (1990) Presynaptic mechanism for long-term potentiation in the hippocampus. Nature 346 : 724-729.

Blackstad TW (1956) Commissural connections of the hippocampal region in the rat, with special reference to their mode of termination. J Comp Neurol 105:417-537.

Desmond NL, Levy WB (1990) Morphological correlates of long-term potentiation imply the modification of existing synapses not synaptogenesis, in the hippocampal dentate gyrus. Synapse 5:139-143.

Edwards F (1991) LTP is a long term problem. Nature 350:271-272.

Foster TC, McNaughton BL (1991) Long-term synaptic enhancement in hippocampal field CA 1 is due to increased quantal size, not quantal content. Hippocampus 1:79-91.

Friedlander MJ, Sayer RJ, Redman SJ (1990) Evaluation of long-term potentiation of small compounds and unitary EPSPs at the hippocampal CA3-CAl synapse. J Neurosci 10:814-825.

Frotscher M, Schlander M, Leranth C (1986) Cholinergic neurons in the hippocampus. A combined light- and electron-microscopic immunocytochemical study in the rat. Cell Tissue Res 246:293-301.

Harris KM, Stevens JK (1988) Dendritic spines of the rat cerebellar Purkinje cells: serial electron microscopy with reference to their biophysical characteristics. J Neurosci 8:4455-4469.

Harris KM, Stevens JK (1989) Dendritic spines of CA1 pyramidal cells in the rat hippocampus: serial electron microscopy with reference to their biophysical characteristics. J Neurosci 9:2982-2997.

Harris KM, Cruce WLR, Greenough WT, Teyler TJ (1980) A Golgi

$\leftarrow$

Figure 7. Three-dimensional reconstruction of adjacent axonal boutons (triangle, square) synapsing with two dendritic spines from the same parent dendrite (denl) and with one dendritic spine from a different dendrite (den2; see also Fig. 5). One bouton is an MSB (triangle) synapsing with a thin spine and one head of a branched spine $(b 1)$ arising from the second dendrite. Both dendrites are dark blue, all spines are a lighter blue, axons are white, and onc PSD that is visible on branch $2(b 2)$ is yellow.

Figure 8. Three-dimensional reconstructions of MSBs and their associated dendritic spines in s. radiatum. $a$, MSB synapsing with two spines of grossly different sizes that arise from different dendritic segments (not illustrated). $b$, MSB synapsing with a thin spine and a thin branch (b1) of a branched spine, the second head $(b 2)$ of which synapses on a different axon (not illustrated). Both of these spines arise from different dendritic segments. $c$, An MSB synapsing with three spines (one mushroom spine and two thin spines). The two thin spines arise from the same dendrite (not illustrated) while the large mushroom spine arises from a different dendritic segment (also not illustrated). $d$, MSB synapsing with one branch of a branched spine and a short spine. These spines arise from different dendrites of the same cell. All spines are blue, PSDs are yellow, and the axonal boutons are translucent (gray) to illustrate the spine shapes and their PSDs through them. Scale bar in $d$ is for $a-d$. 
impregnation technique for thin brain slices maintained in vitro. $\mathbf{J}$ Neurosci Methods 2:363-371.

Harris KM, Jensen FE, Tsao B (1992) Three-dimensional structure of dendritic spines and synapses in rat hippocampus (CAl) at postnatal day 15 and adult ages: implications for the maturations of synaptic physiology and long-term potentiation. J Neurosci 12:26852705 .

Hebb DO (1949) The organization of behavior, p 335. New York: Wiley.

Kelly PT, McGuiness TL, Greengard P (1984) Evidence that the major PSD protein is a component of a calcium/calmodulin dependent protein kinase. Proc Natl Acad Sci USA 81:945-949.

Kennedy MB, Bennett MK, Bulleit RF, Erondu NF, Jennings VR, Miller SC, Molloy SS, Patton BL, Schenker LJ (1990) Structure and regulation of type II calcium/calmodulin-dependent protein kinase in central nervous system neurons. Cold Spring Harbor Symp Quant Biol 50:101-110.

Korn H, Faber DS (1991) Quantal analysis and synaptic efficacy in the CNS. Trends Neurosci 14:439-445.

Kullman DM, Nicoll RA (1992) Long-term potentiation is associated with increases in quantal content and quantal amplitude. Nature 357: 240-244.

Larkman A, Stratford K, Jack J (1991) Quantal analysis of excitatory synaptic action and depression in hippocampal slices. Nature 350: 344-347.

Larkman A, Hannay T, Stratford K, Jack J (1992) Presynaptic release probability influences the locus of long-term potentiation. Nature 360 : 70-73.

Lorente de No R (1934) Studies on the structure of the cerebral cortex. II. Continuation of the study on the ammonic system. J Psychol Neurol 46:113-177.

Malinow R (1991) Transmission between pairs of hippocampal slice neurons: quantal level, oscillations and long-term potentiation. Science 252:722-724.

Malinow R, Tsien R (1990) Presynaptic enhancement shown by whole cell recordings of long-term potentiation in hippocampal slices. Nature 346:177-180.

Manabe T, Renner P, Nicoll RA (1992) Postsynaptic contribution to LTP revealed by the analyses of miniature synaptic currents. Nature 355:50-55.

Pearlstein RA, Kirschner L, Simons J, Machell S, White WF, Sidman
RL (1986) A multimodal system for reconstruction and quantification of neurologic structures. Anat Quant Cytol Histol 8:108-1 15.

Powell EW (1963) Septal efferents revealed by axonal degeneration in the rat. Exp Neurol 8:406-422.

Ramon y Cajal S (1911) Histologie du systeme nerveux de l'homme et des vertebres, vol 2. Paris: Malione.

Redman SJ (1990) Quantal analysis of synaptic potentials in neurons of the central nervous system. Physiol Rev 70:165-198.

Sayer RJ, Friedlander MJ, Redman SJ (1990) The time course and amplitude of EPSPs evoked at synapses between pairs of $\mathrm{CA} 3 / \mathrm{CA} 1$ neurons in the hippocampal slice. J Neurosci 10:826-836.

Schaffer K (1892) Beitrag zur Histologie der Ammonshornformation. Arch Mikrosc Anat 39:611-632.

Schlander M, Frotscher M (1986) Non-pyramidal neurons in the guinea pig hippocampus: a combined Golgi-electron microscope study. Anat Embryol (Berl) 174:35-47.

Siekevitz P (1985) The postsynaptic density: a possible role in longlasting effects in the central nervous system. Proc Natl Acad Sci USA 82:3494-3498.

Swann JW, Gomez CM, Rice FL, Smith KL, Turner JN (1991) Anatomical study of $\mathrm{CA} 3$ hippocampal neurons and networks during postnatal development. Soc Neurosci Abstr 17:450.13.

Tamamaki N, Nojyo Y (1991) Crossing fiber arrays in the rat hippocampus as demonstrated by three-dimensional reconstruction. $\mathrm{J}$ Comp Neurol 303:435-442.

Trommald M, Vaaland JL, Blackstad TW, Andersen P (1990) Dendritic spine changes in rat dentate granule cells associated with longterm potentiation. In: Neurotoxicity of excitatory amino acids (Guidotti AM, ed), pp 163-174. New York: Raven.

Wallace C, Hawrylak N, Greenough WT (1991) Studies of synaptic structural modifications after long-term potentiation and kindling: context for a molecular morphology. In: Long-term potentiation: a debate of current issues (Baudry M, Davis JL, eds), pp 189-232. Cambridge, MA: MIT Press.

Westrum LE, Blackstad TW (1962) An electron microscopic study of the stratum radiatum of the rat hippocampus (regio superior CA1) with particular emphasis on synaptology. J Comp Neurol 119:281292.

Voronin LL, Kuhnt U, Hess G (1990) Quantal analysis of long-term potentiation of combined neuronal postsynaptic potentials on hippocampal slices in vitro. Neurophysiology 22:341-347. 